\title{
5. 'We look after our own': The cultural dynamics of celebrity in a small country
}

\section{ABSTRACI}

Unlike the United Kingdom, the United States and Australia, where celebrities are often subjected to derision in the tabloid media, the New Zealand Woman's Weekly, the country's longest-running women's magazine, respects and values its local celebrities. A content analysis of cover lines on the magazine over the past eight decades reveals that although the magazine has adhered to a steadfast formula of celebrating mothers and wives, there has been a steady shift to a focus on the love lives and scandals of foreign celebrities. More recently, however, the magazine has turned its attention to well-known New Zealanders and developed its own brand of celebrity news.

Keywords: celebrification, celebrity, content analysis, gossip, sensationalism, tabloidisation

\section{JEREMY OLDS and LYN BARNES \\ Auckland University of Technology}

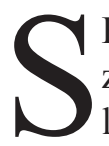

ENSATIONALISM has become clearly visible in the tabloid magazine industry (Nice, 2007). The practice of reporting on the private lives of celebrities is now common in women's magazines, including the longest-running weekly magazine in New Zealand, the New Zealand Woman's Weekly. Magazines that concentrate on celebrification are sometimes referred to as gossip magazines (Nice, 2007), as the content is often scandalous news about absent third parties (Foster, 2004).

To identify the increase in sensationalism and celebrification in the New Zealand Woman's Weekly, this article analyses the cover lines over the 81-year history of the publication and confirms earlier findings. A 2012 investigation revealed there was a distinct type of sensationalism present in the 'Weekly', 
which manifests itself in a different way to how it does elsewhere in the world (Olds, 2012). The study also found differences in the way New Zealand celebrities are treated compared to foreigners. This article argues there has been a shift in how values are transferred to magazine readers, as evident through the manifestation of celebrities, affirming that, as with other magazines, the New Zealand Woman's Weekly mirrors the social, political and economic values of the time and place (Schwabe, 2008; Johnson, 2002; Kitch, 2003).

We first define the notion of tabloid magazines and how the concepts of sensationalism, celebrity and gossip play a role. This is followed by a content analysis of the six covers. We then discuss the results of the analysis. Finally we focus on a specific aspect emerging from the content analysis; how, although the content has changed, the objective of creating and maintaining traditional 'Kiwi' values is constantly reinforced through the positive portrayal of local celebrities.

\section{Hear all about it}

Tabloid publications tend to personalise stories, feature numerous stories per page and have an emphasis on visual material such as photographs, graphics, headlines, typography and colour (Nice, 2007). Text on these covers, especially cover lines, is designed to capture readers' attention and interest in a very small timeframe (McKay, 2006). Readers on average spend between three and five seconds scanning a magazine cover before deciding whether to buy it or not (Quigley, 1988). Media producers may consciously use content-rich words and images based on what they believe captures the attention of audiences (Brewer, 2009). This is where sensationalism plays an important role. Sensationalism is a journalistic phenomenon where news content is treated so as to cause interest or excitement among audiences (Sensationalism, 2005). Sensational content is designed to elicit attention from audiences by way of the news topic or the way in which it is presented (Grabe, Zhou \& Barnett, 2001).

Sensational news has wide appeal (Vettehen, Nuijten \& Beentjes, 2005). While some critics (Bernstein, 1992; Franklin, 1997) contend that sensational news is trivial, shallow and condescending, others (Hardy, 2011) believe critics have been disingenuous, and contend that in buying tabloid newspapers and celebrity magazines, we are 'satisfying a primal evolutionary need' (Hardy, 2011, p. 23). Donohew, Palmgreen \& Duncan (1980) believe people have a biological need for stimulation, whether emotional or informational, 


\section{CELEBRITY AND SCANDAL}

and they derive pleasure when these desires are met. Vettehen, et al. (2005) call this 'sensation seeking' (p. 322) behaviour, and say that people look for information that will provide them with an optimum level of arousal. When arousal drops below or exceeds this level, audiences tend to react negatively to the source of information and stop paying attention (Donohew, et al., 1980). In this situation, media content is the information source audiences use to satisfy some need, such as information or entertainment.

Sensationalism is not new. Sloan (2001) notes that sensationalism predates the first newspaper, produced in Germany in 1609. It was present in the stories of Shakespeare. In the 19th century, the penny press - cheap, tabloid-style newspapers - was criticised for producing unabashedly emotional, crude content (Örnebring \& Jönsson, 2004). News topics revolved around the same sensational themes of crime, scandal and gossip, but employed a crusading tone. This led to a more aggressive investigative reporting style in the early 20th century known as 'muckraking', where journalists advocated for change and served as public watchdogs (Sterling \& Fellow, 2009). Topics of modern day sensational stories tend to revolve around disasters and elite people (Grabe, et al, 2001). Therefore, sensationalism can be regarded as an evolving phenomenon, rather than a phenonomenon of contemporary journalism (Grabe et al., 2001).

Investigative journalist Carl Bernstein (1992), who helped to uncover the Watergate scandal in the 1970 s, describes sensational journalism as perpetuating an 'idiot culture' (p. 25). At the most extreme, critics (e.g. Grabe, et al., 2001; Örnebring \& Jönsson, 2004) say news of this nature may be a threat to democracy.

Bird (1992) suggests sensationalism may be perceived as representing a moral slippage and a collapse of the value system associated with traditional journalism - honesty, accuracy and fairness. Alternatively, a number of scholars (e.g. Slattery, 1994; Hermes, 1995) perceive the effects of sensationalism in a positive light, arguing it performs an important function in society. Sensational content may enforce social standards of decency and morality by demonstrating what is regarded as unacceptable behaviour (Slattery 1994; Slattery, et al, 2001). Hermes (1995) discusses how such content can be a means of sharing judgment, helping communities to construct and reinforce a moral consensus. The consumption of sensational news gives audiences the chance to reflect on their own lives and reinforce or adjust their moral 
standards. Sensationalism will vary between cultures. For example, in the United Kingdom, members of the royal family are treated as celebrities and often feature on tabloid magazine covers.

Rojek (2001) identifies three categories of celebrity: ascribed, which includes those people whose celebrity status stems from their lineage, such as members of the royal family; achieved, which refers to those who are well known for their accomplishments, excellence or skill, such as actors or musicians; and attributed, which includes those people whose fame is largely due to media attention, or, as Boorstin (1961) puts it: 'well-known for their well-knownness' (p. 57). It is this category that authors (Furedi, 2010; Drake $\&$ Miah, 2010) perceive many contemporary celebrities to fall into. Instead of referring to skilled, talented and exceptional performers, celebrity is now used to refer to people known foremost for their public profile. Celebrity is more than a noun - it denotes the quality of attracting attention (Furedi, 2010).

Olds (2012) points out that missing from Rojek's conceptualisation is an exploration of celebrity as a mediated construct. Celebrities are labelled as such only so long as the public has an appetite for news about them, whether or not they are skilled (p. 22). 'Media exposure is the oxygen that sustains the contemporary celebrity' (Drake \& Miah, 2010, p. 55). Celebrity news offers the public what Horton \& Wohl (1956) describe as para-social interactions, in that audiences can form a bond and identify with celebrities, despite them remaining largely inaccessible. This is because traditional media are largely one-way systems of communication, meaning celebrities can appear ordinary, everyday people and are easily consumed, yet remain distant from audiences (Drake \& Miah, 2010), although this has changed with the development of social media (Krotoski, 2011).

One of the key criticisms of tabloidisation is that an increasing amount of coverage is devoted to news about celebrities. Celebrity news can be linked with the news value that is placed on elite persons. Audiences have a level of interest in public figures, so the more important the person, the more newsworthy they are deemed to be (Sissons, 2008). The actions of celebrities are perceived to be of greater significance and consequence, and people follow their lives to catch a glimpse into their world (Gorin \& Dubied, 2011). Although most audiences will never meet these people, the intimate details and personal insights revealed about celebrities' lives give readers the opportunity to establish a connection and reflect on their own identity (Wilson, 


\section{CELEBRITY AND SCANDAL}

2010). Despite living worlds apart, the proximity and intimacy fostered by celebrity news makes celebrities seem relatable, and audiences are encouraged to identify with them (Gorin \& Dubied, 2011). Increasingly, however, audiences are not being invited to identify with celebrities so much as being encouraged to make moral judgments about their private lives (Wilson, 2010).

For a story to be considered celebrity news, Gorin \& Dubied (2011) identified five criteria it must fulfil. The story must centre on the celebrity figure as a character in a narrative; the figure must have a 'dual persona', balancing their glamorous professional life with more relatable aspects of their personalities; this double life must be supported by a balance between the figure's public profile and their personal life; the figure must exhibit qualities in line with what it means to be a celebrity, whether their personal attributes or their lifestyle; and the stories must be produced using journalistic techniques and guidelines (p. 600). Olds (2012) asserts that these criteria are useful as they the concept of celebrity as a construct to the way people consume it, acknowledging aspects of audience identification, associability and a distinction between reality and representation.

There was a marked increase in fascination with celebrity culture during the 20th century, particularly after the pioneers of the penny press in America with the emergence of cinema, radio, and later television and the internet, increased the circulation and visibility of celebrities (Drake \& Miah, 2010). Magazines began focusing on the private lives of film stars in the 1910s, as audiences wanted to engage with these figures outside their screen lives (Wilson, 2010).

Audiences began to develop an appetite for celebrity news and a hunger for images and information about every aspect of their lives (Alexander, 2010). Cashmore (2006) contends that the 1960s were the beginning of a new enchantment with celebrities, to the point of becoming a secular religion.

We, the consumers, have become fascinated, often to the point of prurience, with the well-chronicled lives. Celebrities have become godlike objects to us and we seem to delight in their sense of self-importance, their scandulous behaviour and their eagerness to deplore the media's intrusions, while inciting their interest with any device available. (Cashmore, 2006, p. 266). 
What became clear to news producers was that celebrity content sold. Celebrities could be developed to make money.

In a capitalist economy, where the primary objective of news media owners is to make a profit, content that sells is an important, money-making asset, and sensationalism is perceived to be one tactic in achieving this goal (Grabe, et al, 2001). It made sense also to develop celebrities as they had important social functions, or as Marshall (1997) explains, celebrities are not just people, they are influential representatives, for example, with product endorsements.

\section{What's the 'goss'?}

People often engage in gossip, which is popularly understood to mean conversation and subsequent judgments about people who are absent (Foster, 2004). Gossip evolved in a village society, where it was easily transmitted from person to person, but in today's global village, Hardy (2011) endorses the press as a distributing mechanism. The development of gossip in magazine covers suggests that the magazine content increasingly invites audiences to make evaluations of people who are not present, based on the information provided by the magazine (Olds, 2012). While gossip may be considered negatively, some researchers assert it in fact plays an important social function that enables people to form relationships with those they are communicating with, exercises their values in order to strengthen their identity and sets expectations about norms and behaviour (Foster, 2004; Wert \& Salovey, 2004).

Despite being widespread, the practice of gossip is often explicitly sanctioned by society, which popularly associates it with questionable ethics (Foster, 2004). Bok (1983) sees gossip as a breach of privacy and, consequently, morally indefensible.

Foster (2004) suggests gossip also has an evaluative component. Rather than the mere spreading of news, conceptualisations of gossip carry with them implications of a positive or negative judgment. People have an innate desire to evaluate their attitudes and opinions against real-world criteria (Festinger, 1954). When such information is not available, they may look to others for affirmation of their competence. People may compare their own characteristics to those of others in search of self-evaluation, improvement, enhancement and identity strengthening (Wert \& Salovey, 2004). Thus, gossip involves an aspect of social evaluation, comparison and judgment (Olds, 2012). So what may seem 


\section{CELEBRITY AND SCANDAL}

to be nothing more than water-cooler banter may in fact play an important role in the way people understand the world and themselves (Olds, 2012; Wert \& Salovey, 2004). The question of why people gossip is a more multifarious issue. As previously alluded to, gossip allows people to gain an understanding of their social environment, so information exchange is an important dimension of its function (Brewer, 2009). At the same time, people clearly derive some pleasure in gossiping and Spacks (1982) notes that most who participate do so for the sheer fun of it. Therefore, gossip has some entertainment value and the practice has an element of recreational fun (Foster, 2004).

Sharing gossip with someone denotes a sense of intimacy, confidence and trust (Foster, 2004). Additionally, many authors note the influence function of gossip - the effort to negotiate standards of decency and determine whether a third party violates them (Foster, 2004; Wert \& Salovey, 2004). In this sense, our expectations of behaviour and norms are learned through gossip (Olds, 2012). It is this dimension of gossip that leads to the scurrilous reputation of the phenomenon - breaches of social expectations are likely to feature in future gossip (Foster, 2004). However, as explored above, gossip has the ability to not only divide but also foster a sense of identity, and so has both positive and negative attributions (Olds, 2012).

Former editor of New Zealand Woman's Weekly Sido Kitchin (2011) realised she had overstepped the mark with readers when they objected to her featuring former All Black Matthew Ridge, and former lover of David Beckham, Rebecca Loos, on the cover of the magazine 'cavorting half-naked on a beach'.

Judging what is acceptable and not acceptable is a balancing act.

There was much debate about whether to put Jools Topp [one of the lesbian twin sisters in the singing-comedy Topp Twins duo] on the cover last year when she revealed she had lost her breast to cancer, but I fought for it on the grounds it was a news story and Jools is heartland New Zealand. (Kitchin, 2011)

Another aspect of gossip is the idea that people look for self-improvement by comparing themselves to those they aspire to be (Wert \& Salovey, 2004). People are curious about those who have more power than they do and, by gossiping about them, people are able to compare themselves to them without the humiliation of doing so face-to-face (Wert \& Salovey, 2004). This is called upward social comparison (Wert \& Salovey, 2004) and, while

92 PACIFIC JOURNALISM REVIEW 19 (2) 2013 
stemming from ambition and aspiration, can lead to feelings of envy, jealousy and resentment.

\section{Stick to its knitting: Different stitches}

The New Zealand Woman's Weekly is an appropriate publication for analysis. The magazine has a longstanding history of providing readers with content that reflects their interests and values (Lynch, 2002), and now operates in a fiercely competitive industry where sensationalist tactics are rife (Bird, 1992). In order to understand how sensationalism functions in a New Zealand context, it is valuable to use a publication where sensationalism may be expected, as to best recognise the way in which sensationalism manifests itself and what the effects of this are.

The magazine, which was launched in December 1932 during the Great Depression, aimed to 'preach the gospel of usefulness, cheerfulness and happiness. Its mission is to teach, to entertain, to assist and to amuse: its objective, to become a national family journal in the truest sense of the word' (New Zealand Woman's Weekly, 1932, p. 6). Following this formula, it reached its highest circulation figures in 1982 at 251,854 (ABC, 2012). Today the New Zealand Woman's Weekly is one of the widest-read consumer publication in the country (APN, 2012). Statistics from the New Zealand Audit Bureau of Circulation Inc indicate the magazine has an average net circulation of 73,516, and an average of 808,000 weekly readers (ABC, 2012). Its website says it is aimed at women 30 years and older and is the second most important consumer title for New Zealand mothers (APN, 2012).

Whereas the New Zealand Woman's Weekly was once filled with stories about sewing, cooking and other domestic activities, it now focuses more on celebrity news content, and stories that promise to reveal information about the private lives of celebrities (Olds, 2012). But it is how celebrities are portrayed that is important to sales of the magazine. As former editor Kitchin commented in 2011, when choosing what to put on the cover, she used weekly circulation figures for guidance and looked at overseas trends.

We worship celebrity engagements, weddings and babies, which are always sure-fire winners. Eight out of 10 of my top-selling covers last year were local stars, while mostly it's international stars who top my Aussie competitors' lists. The royals are winners for the Weekly, but magazine sales have never returned to the height they reached when Princess Diana graced the covers. (Kitchin, 2011)

PACIFIC JOURNALISM REVIEW 19 (2) 201393 


\section{Methods}

Media researchers have a long history of employing content analysis as a method, and the technique has long been associated with journalism research (Rose, 2007). Content analysis is based on a number of guidelines which, when followed rigorously, produce data that allow for reliable and valid inferences that relate to the context they are used in (Krippendorf, 2004; Rose, 2007). Content analysis commonly looks at cultural texts, typically in regard to the linguistic references, attitudes expressed and other evaluations present (Krippendorf, 2004), but also visual material (Rose, 2007). This means analysts are sensitive to the broader cultural context in which data exist (Rose, 2007). With content analysis, analysts need to select a sample and investigate the meanings within them in light of the context in which they are used. They must ensure their chosen contexts are made explicit so all results are meaningful to their peers and to those who will find them meaningful. Analysts may choose to concentrate on a certain person, place, object or theme in the text and explore these in depth. Content analyses are frequently comparative, and the method is used to test a hypothesis across a number of texts.

The method of content analysis is ideal for investigating the meaning of media texts as it allows researchers to make judgments based on what is represented in the content (Bell, 2001). However, by choosing certain texts to analyse, the researcher excludes others, which will invariably have consequences on any conclusions they may draw. In this research study, the cover

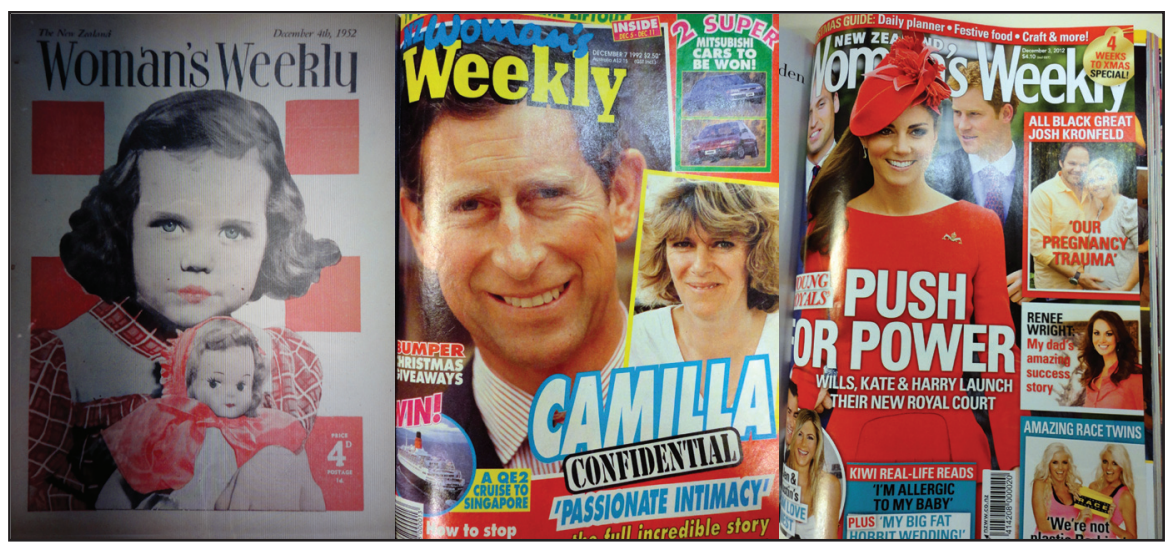

Figure 1: Woman's Weeklymagazine covers:4December 1952,7 December 1992 and 3 December 2012.

94 PACIFIC JOURNALISM REVIEW 19 (2) 2013 
lines - the words used on the cover to promote the content - are considered. Data can then be analysed to identify patterns, trends or differences across the comparative texts. Inferences and judgments can then be made to explain the data. In doing so, analysts go beyond the data and make evaluations that incorporate the broader context of the text. By interpreting this quantification, researchers can draw meaningful and valid conclusions about the data.

Research on sampling is limited (Riffe, Aust \& Lacy, 1993). However, constructed sampling is recommended rather than random sampling. To determine patterns and themes that would provide insight into how sensationalism is manifested and whether the manifestation has changed over time in the New Zealand Woman's Weekly, Olds (2012) observed specific themes in the magazine's covers for his honours dissertation. He chose three issues dated from the first issue in December 8, 1932, then at 40-year intervals from the same time period of each year, namely December 4, 1972, and December 5, 2011.

This study builds on his investigation by looking at covers from the intervening 20-year intervals, again from the same period in early December: December 4, 1952 and December 7, 1992, and a year later on after Olds issue of analysis, December 3, 2012 (see Figure 1).

Using content analysis, once the timeframe is established, context units for coding are identified. In both studies codes were used to analyse the covers based on the physical, syntactical, categorical, propositional and thematic properties of the cover content. For example, the variable 'story topic' refers to the thematic category in which each of the cover line stories could be placed. The values are celebrity, meaning cover lines concerned with the lives or activities of celebrities; domestic, referring to cover lines denoting content concerning household tasks or activities such as cooking and craftwork; fashion, relating to cover lines about clothing and patterns; health, meaning topics concerning diet and medical health; and miscellaneous, for cover lines where the topic of the content was not easily identifiable.

Other variables concerning content include the number of images and the number of people represented on the cover. Variables that coded the treatment of content include image size, the number of images, word types and in some cases colour.

This article has selected key variables to reproduce here that are relevant to the argument. Olds' (2012) study also considered image size and style of the model image, including gaze. This study concentrates only on cover lines. 
CELEBRITY AND SCANDAL

Table 1: Story topics

\begin{tabular}{|l|c|c|c|c|c|c|}
\hline Magazine issue & 1932 & 1952 & 1972 & 1992 & 2011 & 2012 \\
\hline Celebrity & 0 & 0 & 1 & 1 & 6 & 5 \\
\hline Domestic & 3 & 0 & 3 & 0 & 0 & 0 \\
\hline Fashion & 3 & 0 & 0 & 0 & 0 & 0 \\
\hline Health & 0 & 0 & 1 & 1 & 0 & 1 \\
\hline Promotional offers & 0 & 0 & 2 & 0 & 0 & 0 \\
\hline Miscellaneous & 2 & 1 & 0 & 4 & 1 & 3 \\
\hline TOTAL & 8 & 1 & 7 & 6 & 7 & 9 \\
\hline
\end{tabular}

\section{Table 2: Story subjects}

\begin{tabular}{|l|c|c|c|c|c|c|}
\hline Magazine issue & 1932 & 1952 & 1972 & 1992 & 2011 & 2012 \\
\hline People & 0 & 1 & 1 & 2 & 7 & 10 \\
\hline Not people & 8 & 0 & 4 & 5 & 1 & 4 \\
\hline TOTAL & 8 & 1 & 5 & 7 & 8 & 14 \\
\hline
\end{tabular}

\section{Table 3: Number of images}

\begin{tabular}{|l|c|c|c|c|c|c|}
\hline Magazine issue & 1932 & 1952 & 1972 & 1992 & 2011 & 2012 \\
\hline Photographs & 1 & 1 & 1 & 4 & 7 & 7 \\
\hline
\end{tabular}

\section{Table 4: People represented}

\begin{tabular}{|l|c|c|c|c|c|c|}
\hline Magazine issue & 1932 & 1952 & 1972 & 1992 & 2011 & 2012 \\
\hline No. of people & 1 & 1 & 2 & 2 & 15 & 10 \\
\hline
\end{tabular}

\section{Table 5: Nationalities}

\begin{tabular}{|l|c|c|c|c|c|c|}
\hline Magazine issue & 1932 & 1952 & 1972 & 1992 & 2011 & 2012 \\
\hline New Zealanders & 0 & 1 & 0 & 0 & 12 & 3 \\
\hline Foreigners & 1 & 0 & 2 & 2 & 3 & 7 \\
\hline TOTAL & 1 & 1 & 2 & 2 & 15 & 10 \\
\hline
\end{tabular}

\section{Table 6: Number of words}

\begin{tabular}{|l|c|c|c|c|c|c|}
\hline Magazine issue & 1932 & 1952 & 1972 & 1992 & 2011 & 2012 \\
\hline Words & 33 & 0 & 42 & 40 & 42 & 70 \\
\hline
\end{tabular}

Note: excluding masthead, date and price but including numbers and abbreviations.

96 PACIFIC JOURNALISM REVIEW 19 (2) 2013 


\section{Going under cover}

1932

Three of the eight cover lines of the 1932 edition of the New Zealand Woman's Weekly relate to fashion features; three relate to content about domestic activities, and the remaining two concern fictional content. In the 1932 issue there is no evidence of celebrity news on the cover as there are no stories about people. Instead, its focus is on the lives of New Zealand women and their role and responsibilities of the times (such as cooking, sewing and craft work). It fosters a sense of identity and inclusion based on these topics, by reflecting the country and its readers (Olds, 2012).

\section{2}

Twenty years later, there is still no evidence of celebrities and no cover lines pertaining to the content. Instead, a single image of a neatly dressed Caucasian girl, who is probably three to five years old, cuddles her doll. This hints that content may relate to children but otherwise there are no clues to the content.

\section{2}

This is the first issue in this analysis to show evidence of a celebrity story in its cover lines. The issue has seven cover lines: six cover lines fall into the category of celebrity and one relates to the magazine itself as 'No.1 royal mag' is coded under miscellaneous. Two of the cover lines that could be considered sensational with regard to content: 'IS BUTTER REALLY A KILLER?' presupposes a suggestion that butter may be linked to death and 'DAVID FROST AND DIAHANN CARROLL SAY THEY'LL MARRY' suggests elements of scandal, celebrity and romance, which are considered sensational (Olds, 2012; Slattery, 1994). The use of negative terms is in contrast to earlier issues. The cover line 'MAKE A GIFT... DIRECTIONS INSIDE' directly addresses the reader and engages them in the content, rather than simply stating the content, which may be considered sensational (Olds, 2012).

Another interesting observation in the 1972 issue is that the magazine's focus has begun to shift abroad, to overseas celebrities. Based on all the cover lines it seems that, while most stories are still focussed on the role and responsibilities of the New Zealand woman (the health of the family and the home), the magazine's attention has begun to drift offshore and tap into celebrity culture. 


\section{CELEBRITY AND SCANDAL}

The cover line 'DAVID FROST AND DIAHANN CARROLL SAY THEY'LL MARRY' fulfils Gorin \& Dubied's (2011) five criteria of celebrity news. The story centres on celebrities David Frost and Diahann Carroll. They are celebrities known for their talent and excellence, which Rojek (2001) categorises as those who have achieved their celebrity status. At the time, Diahann Carroll was starring in the American sitcom, Julia. David Frost, a well-known journalist, had visited Auckland in September, 1972. But rather than focus on their professional careers, the cover lines refer to relationship - their dual persona (Gorin \& Dubied, 2011). This gives an insight into their private lives, which complements readers' knowledge of their public profile (Olds, 2012). 1992

The cover lines on the 1992 issue of New Zealand Woman's Weekly direct readers to six stories. One relates to 'celebrity' (CAMILLA CONFIDENTIAL 'PASSIONATE INTIMACY'- the full incredible story of Charles' other woman); one relates to health (How to stop smoking and stay slim); three relate to special promotional offers (2 SUPER MITSUBISHI CARS TO BE WON!; BUMPER CHRISTMAS GIVEAWAYS; WIN! A QE2 CRUISE TO SINGAPORE); and one can be classified as miscellaneous (TV TODAY PROGRAMME LIFTOUT INSIDE). There is significant variance in the typography used between cover lines, with adjectives (WIN!; BUMPER; SUPER; INSIDE) generally emphasised in bold, as though shouting at the reader, and a contrasting colour. There is a total of five images. The largest is a close-up photograph of Charles' face. The second largest image is a close-up portrait photograph of Camilla. The photograph overlaps the image of Charles, at a slightly tilted angle. Charles is a prince, and the gossip and scandal at the time revolved around the couple's extra-marital relationship. The quotation marks around 'PASSIONATE INTIMACY' indicate that an informant is being directly quoted in the article (Brewer, 2009.) What is evident immediately on the cover of this issue is the promotional offers - for two cars and a cruise- that were not present on the covers of earlier editions. By this time, international titles began to be sold in New Zealand so there was competition from Australianproduced Woman's Day which was first sold here in 1989, and New Idea.

\section{1}

The 2011 cover features seven images. The primary image is a full-page photograph of Pippa Middleton. Near the centre of this image is the main cover line ('The PIPPA PROBLEM Palace outrage over bad behaviour').

98 PACIFIC JOURNALISM REVIEW 19 (2) 2013 
Three photos are positioned along the left side of the page. The first is a staged portrait of Zinzan Brooke, his wife Alison and their seven children. Underneath this image is the corresponding headline ('THIS IS MY LIFE' Zinzan's reality TV family'). Underneath this is an inserted photograph of Demi Moore wearing sunglasses. Inside this photograph is the cover line 'Demi plots revenge'. In the bottom left corner of the cover is a small photograph of Rena Owen with the words 'RENA OWEN'S SEARCH FOR LOVE'. In the bottom right corner of the cover is a photograph of Brian and Tracey Marceau, the parents of murdered teenager Christie. Inserted on top of this image is a small photo of Christie Marceau. Within the image of Brian and Tracey are the corresponding headlines: EXCLUSIVE Murdered teen Christie Distraught parents speak'. On the right side of the cover, above the middle, is an inserted photograph of Kate Middleton. She is pictured at a supermarket checkout handling groceries, with the cover line: 'WHAT'S IN KATE'S TROLLEY? Find out inside!'

A total of 15 people are represented on the cover, significantly more than either of the previous issues. Of these 15 people, three of them are not from New Zealand.

This suggests the magazine has shifted its attention from foreign celebrities to reflect the celebrity culture that exists in New Zealand. The national celebrities are represented with understanding and appreciation, whereas the portrayal of foreign celebrities encourages readers to make critical judgments on their behaviour rather than empathise with them (Olds, 2012).

There are numerous instances of sensationalism in the 2011 cover. With regards to topic, six of the seven cover lines relate to celebrity stories. The content focuses on celebrities' bad behaviour (Pippa Middleton), traumatic experiences (Brian and Tracey Marceau) quests for love (Rena Owen) or revenge (Demi Moore) and speculates about their actions (Kate Middleton). Olds (2012) proposes that the stories are angled this way to promote themes that have moral components, and thus can be considered sensational. Further, the formal dimensions of the cover, such as text and imagery, are manipulated so as to make the content appear sensational. Each cover line concerning celebrities is accompanied by at least one image, putting a face to the story. There are several instances of value-laden language: 'Demi plots revenge', 'The PIPPA PROBLEM Palace outrage over bad behaviour', 'EXCLUSIVE Murdered teen Christie Distraught parents speak'. These words are used to make stories appear more appealing and dramatic, and also angle the content 


\section{CELEBRITY AND SCANDAL}

towards moral issues on which gossip can take place (Olds, 2012). Readers are addressed directly 'Find out inside', and interjections such as 'PLUS' and 'EXCLUSIVE' suggest readers are getting valuable extra content.

The six stories mentioned on the cover, which refer to celebrity news stories, conform to Gorin \& Dubied's (2011) definition of celebrity news. For example, the story 'Demi plots revenge' focused on Demi Moore, a well-known Hollywood actress. The cover line does not refer to her professional life, but her personal issues. It is not explicitly stated why Demi is plotting revenge, or who the revenge is directed at. Instead, readers are entrusted to make a causal connection between this story and her recent separation from husband Ashton Kutcher, following his alleged infidelity (Olds, 2012). While this connection is not supported by visual or verbal representation on the cover, the story was widely discussed in the media at the time of publication and readers may infer this story to be a new angle in the coverage of the separation. This suggests the magazine expects readers to have pre-existing knowledge of the celebrities represented and their personal lives.

Olds (2012) contends the New Zealand Woman's Weekly is fostering a relationship where celebrities are the topic of on-going gossip. He notes that only one of the celebrities on the cover (Rena Owen) is referred to by her full name. All other people are represented by their first name-Zinzan, Pippa, Kate, Demi and Christie. This is in contrast to the 1972 issue, where David Frost and Diahann Carroll are referred to by their full name. This first-namebasis referral again reinforces the relationship between the reader and the magazine, assuming there is shared knowledge about the celebrities, which needs not be stated (Olds, 2012).

Referring to these elite people by their first name fosters a sense of intimacy between the magazine and its audience, and assumes its readers are familiar with the celebrities it features. This decrease in formal identification means that, rather than observing celebrities from a distance, the magazine now encourages audiences to identify with celebrities on a personal level, as if they were acquainted with them (Olds, 2012). Readers become covert observers of private lives (Brewer, 2009). 'We call them by their first names, and think we know their motivations and details of their personal relationships' (Brewer, p. 182).

Demi Moore is not represented as a glamorous actress, but as a woman going through a tumultuous break up, an experience not exclusive to

100 PACIFIC JOURNALISM REVIEW 19 (2) 2013 
celebrities. Kate Middleton is not depicted as the Duchess of Cambridge, but as an everyday woman who does her own grocery shopping. At least three of the cover lines support what Cashmore (2006) suggests, that people prefer to read about everyday events in the lives of celebrities, rather than 'fantastic events' in the lives of everyday people (p. 26).

These representations link to Wilson's (2010) comments that celebrity news encourages readers to relate to and identify with stars, despite having no real-world connection to them. By revealing information from the private lives of celebrities, the magazine is providing readers with the opportunity to align themselves with the famous and successful, so they can compare or contrast their own lives and make positive or negative evaluations of the behaviour of the celebrity (Olds, 2012).

As Rojek (2001) asserts, celebrities offer 'peculiarly powerful affirmations of belonging, recognition and meaning' (p. 94).

2012

The main image on this issue is the Duchess of Cambridge dressed in red, superimposed over smaller photographs of Prince William and Prince Harry in the background. The cover lines read 'YOUNG ROYALS PUSH FOR POWER/WILLS, KATE \& HARRY LAUNCH THEIR NEW ROYAL COURT', although the reader is not told what this is about. Down the right-hand side are three smaller images, the first two relating to New Zealand celebrities. In the first, the words ALL BLACK GREAT JOSH KRONFELD heads a photo of the rugby player with his hand on his pregnant wife's stomach as they smile for the camera. The words 'OUR PREGNANCY TRAUMA' suggest the couple share their angst in the magazine relating to the pregnancy. TV personality Renee Wright is pictured smiling alongside the cover line: 'RENEE WRIGHT: My dad's amazing success story'. She is well dressed and made up. The third photo depicts two platinum blonde women with perfect white teeth, smiling. The cover line above them reads AMAZING RACE TWINS 'We're not plastic Barbies'. On the far left is a small image of American actress Jennifer Anniston and her new man actor Justin Theroux, with the words 'Jen \& Justin's 26M LOVE NEST'. A new column in the magazine is promoted in the centre at the bottom of the page: KIWI REAL-LIFE READS followed by two titles in quotation marks: 'I'M ALLERGIC TO MY BABY' PLUS 'MY BIG FAT HOBBIT WEDDING'. Neither these, or the cover lines 'CHRISTMAS GUIDE: Daily planner • Festive food • Craft \& more!' or '4 WEEKS TO XMAS SPECIAL!' 


\section{CELEBRITY AND SCANDAL}

have an associated image. Three New Zealanders and seven foreigners are pictured on the cover.

What is displayed here on this cover highlights what Olds found in his 2012 study; that New Zealanders are portrayed as down-to-earth and relatable every day people, yet they are constructed in a manner that elicits more favourable evaluations. Conversely, foreign celebrities are generally portrayed in a more negative manner. There is respect for Renee Wright's father and empathy for Josh Kronfeld, while readers are invited to cast aspersions on the young royals (especially Kate), compare the blonde Amazing Race Australia contestants to Playboy bunnies, and think of Jennifer Aniston and Justin Theroux as exorbitantly wealthy. Behaviour that would outrage the royal family, while not specified, is depicted negatively, leading readers to judge that the three young royals have acted inappropriately. As Hermes (1995) suggests, sensational content is used as a means of sharing judgment and creating consensus. It is not that readers will necessarily believe the stories, but they are invited to judge those depicted based on their own personal standards. In this way, celebrity news becomes relevant to the lives of the audience (Olds, 2012). What was surprising about this issue was the number of words in the cover lines, 70, which is 28 more than on previous issues analysed.

\section{Discussion}

The findings we have presented here illustrate how cover lines have become increasingly sensational on the covers of the New Zealand Woman's Weekly, particularly in the past 50 years since foreign celebrities began to appear. This follows international trends towards tabloidisation, or more soft news. However, there is a clear delineation between how celebrities are treated in the Weekly. Whereas foreign celebrities are treated with disdain, domestic celebrities are treated as ordinary people and are manifested to reinforce traditional values the magazine has espoused as its mission over its eight-decade history.

In this respect, sensationalism appears to serve a social function, whereby the cover lines provide an opportunity for readers to reflect on their interests and values and engage in communication that reinforces or changes their identity (Olds, 2012). We contend that by focusing on the positive attributes of domestic celebrities, the magazine endorses traditional family values.

There may be other reasons for showing restraint and respect for local celebrities that are outside the scope of this investigation. A possible 102 PACIFIC JOURNALISM REVIEW 19 (2) 2013 
explanation could that be that there is a small pool of talent in New Zealand and strong competition among the three weekly women's magazines, so there would be no point in upsetting them by sensationalising their stories. It could also be because readers react to stories they don't consider appropriate in the Weekly, that they keep the content in check themselves by complaining when the cover lines or content overstep the bounds of what they consider appropriate. In this respect, they are engaging in moral judgments to determine what is socially acceptable.

The main limitation with this study is that it focused on text. There are opportunities for further research by investigating the use of image, particularly the gaze.

What was unexpected in this study, however, was the increase in the number of photographs on the covers and particularly in the number of words, ranging from none to 70 . This could be because of increased competition between the women's magazines, in a desperate bid for more impulse buys. As Olds suggests (2012), findings may be enhanced through a qualitative approach such as interviews, possibly with editors of the New Zealand Woman's Weekly, in order to provide a deeper understanding of how and why sensationalism is used.

\section{References}

ABC. (2012). Magazine audit process. Retrieved November 6, 2012, from http:// magazine.abc.org.nz/audit.html \&type $=2 \&$ titleid $=391 \&$ publisher $=223 \&$ frequen $\mathrm{cy}=5 \&$ sort $=$ t.name $\&$ display $=$.

Alexander, J. C. (2010). The celebrity-icon. Cultural Sociology, 4(3), 323-336.

APN. (2012). About New Zealand Woman's Weekly-APN news and media. Retrieved November 6, 2012, from http://www.apn.co.nz/publication/nz-womans-weekly/ about/

Bell, P. (2001). Content analysis of visual images. In T. van Leeuwen \& C. Jewitt (Eds.), Handbook of visual analysis. London, England: Sage.

Bernstein, C. (1992, June). The idiot culture: Reflections of post-Watergate journalism. The New Republic, 22.

Bird, S. E. (1992). For enquiring minds: A cultural study of supermarket tabloids. Knoxville, TN: University of Tennessee Press.

Bok, S. (1983). Secrets: On the ethics of concealment and revelation. New York, NY: Pantheon Books.

Boorstin, D. (1961). The image: A guide to psuedo-events in America. London, England: Penguin. 


\section{CELEBRITY AND SCANDAL}

Brewer, R. (2009). The 'goss' on Paul and Heather: Attitudes to celebrity and divorce in three NZ women's magazines. Pacific Journalism Review, 15(1), 169-185.

Cashmore, E. (2006). Celebrity / culture. Oxon, England: Routledge

Donohew, L., Palmgreen, P., \& Duncan, J. (1980). An activation model of information exposure. Communication Monographs, 47, 295-303.

Drake, P., \& Miah, A. (2010). The cultural politics of celebrity. Cultural Politics, 6(1), 49-64.

Festinger, L. (1954). A theory of social comparison processes. Human Relations, 7 , 117-140

Foster, E. K. (2004). Research on gossip: Taxonomy, methods, and future directions. Review of General Psychology, 8(2), 78-99.

Franklin, B. (1997). Newzak and the news media. London, England: Arnold.

Furedi, F. (2010). Celebrity culture. Society, 47(6), 493-497

Gorin, V., \& Dubied, A. (2011). Desirable people: Identifying social values through celebrity news. Media, Culture \& Society, 33(4), 599-618

Grabe, M. E., Zhou, S., \& Barnett, B. (2001). Explicating sensationalism in television news: Content and the bells and whistles of form. Journal of Broadcasting and Electronic Media, 45(4), 635-655.

Hermes, J. (1995). Reading women's magazines: An analysis of everyday media use. Cambridge, MA: Polity Press.

Horton, D., \& Wohl, R. R. (1956). Mass communications and parasocial interaction. Psychiatry, 19(3), 215-29.

Johnson, S. (2002). The art and science of magazine cover research. Journal of Magazine \& New Media Research, 5(1). Retrieved May 1, 2013, from http:// aejmcmagazine.arizona.edu/fall2002.html

Keller, J. (2011). Feminist editors and the new girl glossies: Fashionable feminism or just another sexist rag? Women's Studies International Forum 34(1), 1-12.

Kitch, C. (2003). Generational identity and memory in American newsmagazines. Journalism 4(2), 185-202.

Kitchin, S. (2007) Living history. New Zealand Herald, August 11. Retrieved August 7, 2013, from http://www.nzherald.co.nz/journalism/news/article.cfm?c id=63\&objectid=10457197

Krippendorf, K. (2004). Content analysis: An introduction to its methodology (2nd ed.). Thousand Oaks, CA: Sage.

Lynch, J. (2002). New Zealand Woman's Weekly — 70 years: From pavlovas to prime ministers. Auckland, NZ: Random House.

McKay, J. (2006). The magazines handbook. London, England: Routledge.

McNamara, K. (2011). The paparazzi industry and new media: The evolving production and consumption of celebrity news and gossip websites. International Journal of Cultural Studies, 14(5), 515-530.

Nice, L. (2007). Tabloidization and the teen market: Are teenage magazines dumber than ever? Journalism Studies, 8(1), 117-137.

Olds, J. (2012). Under the covers: A content analysis of sensationalism in the New

104 PACIFIC JOURNALISM REVIEW 19 (2) 2013 
Zealand Woman's Weekly. Unpublished honours dissertation AUT University, Auckland.

Örnebring, H., \& Jönsson, A. M. (2004). Tabloid journalism and the public sphere: A historical perspective on tabloid journalism. Journalism Studies, 5(3), 283-295.

Peirce, K. (1990). A feminist theoretical perspective on the socialization of teenage girls through Seventeen magazine. Sex Roles, 23(9/10), 491-500.

Quigley, M W. (1988). What sells, what bombs: Magazine cover roulette. Washington Journalism Review, 10 (6), 18-22.

Riffe, D., Aust, C.F., \& Lacy, S. R. (1993). Effectiveness of random, consecutive day and constructed week sampling. In K. Krippendorff \& M. A. Bock (Eds) (2009) The content analysis reader. Thousand Oaks, CA: Sage.

Rojek, C. (2001). Celebrity. London, England: Reaktion Books.

Rose, G. (2007). Visual methodologies: An introduction to the interpretation of visual materials. (2nd ed.). London, England: Sage

Schwabe, M., Godwin, S., Holden, D., Schrok, D., Thompson, S., \& Wolkomir, M. (2000). Generic processes in the reproduction of inequality: An interactionist analysis. Social Forces, 79(2), 419-453.

Sensationalism. (2005). In key concepts in journalism studies. Retrieved May 1, 2013, from http://ezproxy.aut.ac.nz/login?qurl=http $\% 3 \mathrm{~A} \% 2 \mathrm{~F} \% 2 \mathrm{Fwww}$.credoreference.com/entry/sageukjour/sensationalism

Sissons, H. (2008). Practical journalism: How to write the news. London, England: Sage.

Slattery, K. (1994). Sensationalism versus news of the moral life: Making the distinction. Journal of Mass Media Ethics, 9(1) 5-15.

Slattery, K. L., Doremus, M., \& Marcus, L. (2001). Shifts in public affairs reporting on the network evening news: A move toward the sensational. Journal of Broadcasting and Electronic Media, 45(2), 290-302.

Sloan, B. (2001). I watched a wild hog eat my baby!: A colorful history of tabloids and their cultural impact. Amherst, NY: Prometheus Books.

Spacks, P. M. (1982). In praise of gossip. Hudson Review, 35, 19-38.

Sparks, C. (2000). Introduction: The panic over tabloid news. In C. Sparks \& J. Tulloch (Eds.), Tabloid tales: Global debates over media standards (1-40). Lanham, MA: Rowman \& Littlefield Publishers, Inc.

Sterling, C., \& Fellow, A. (2009). Sensationalism. In Encyclopedia of journalism. (pp. 1281-1284). Thousand Oaks, CA: SAGE Publications, Inc.

Tulloch, J. (2000). The eternal recurrence of new journalism. In C. Sparks \& J. Tulloch (Eds.), Tabloid tales: Global debates about media standards. Oxford and Lanham, MD: Rowman \& Littlefield. pp. 131-146.

Turner, G. (1999). Tabloidization, journalism and the possibility of critique. International Journal of Cultural Studies, 2(1), 59-76.

Vettehen, P., Nuijten, K., \& Beentjes, J. (2005). News in an age of competition: The case of sensationalism in Dutch television news, 1995-2001. Journal of Broadcasting and Electronic Media, 49(3), 282-295. 


\section{CELEBRITY AND SCANDAL}

Wert, S. R., \& Salovey, P. (2004). A social comparison account of gossip. Review of General Psychology, 8(2), 122-137.

Wilson, J. A. (2010). Star testing: The emerging politics of celebrity gossip. Velvet light trap: A critical journal of film and television, 65(1), 25-38

Jeremy Olds graduated with a BCS (Hons) from AUT University, Auckland, in 2013. His journalism has been published in community and national newspapers, magazines and online publications around New Zealand. He currently works as a reporter for New Zealand Doctor.

jeremyolds@gmail.com

Lyn Barnes is a senior lecturer in journalism at AUT University who is currently enrolled in her PhD. Her speciality areas are magazine history and trauma journalism.

Ibarnes@aut.ac.nz

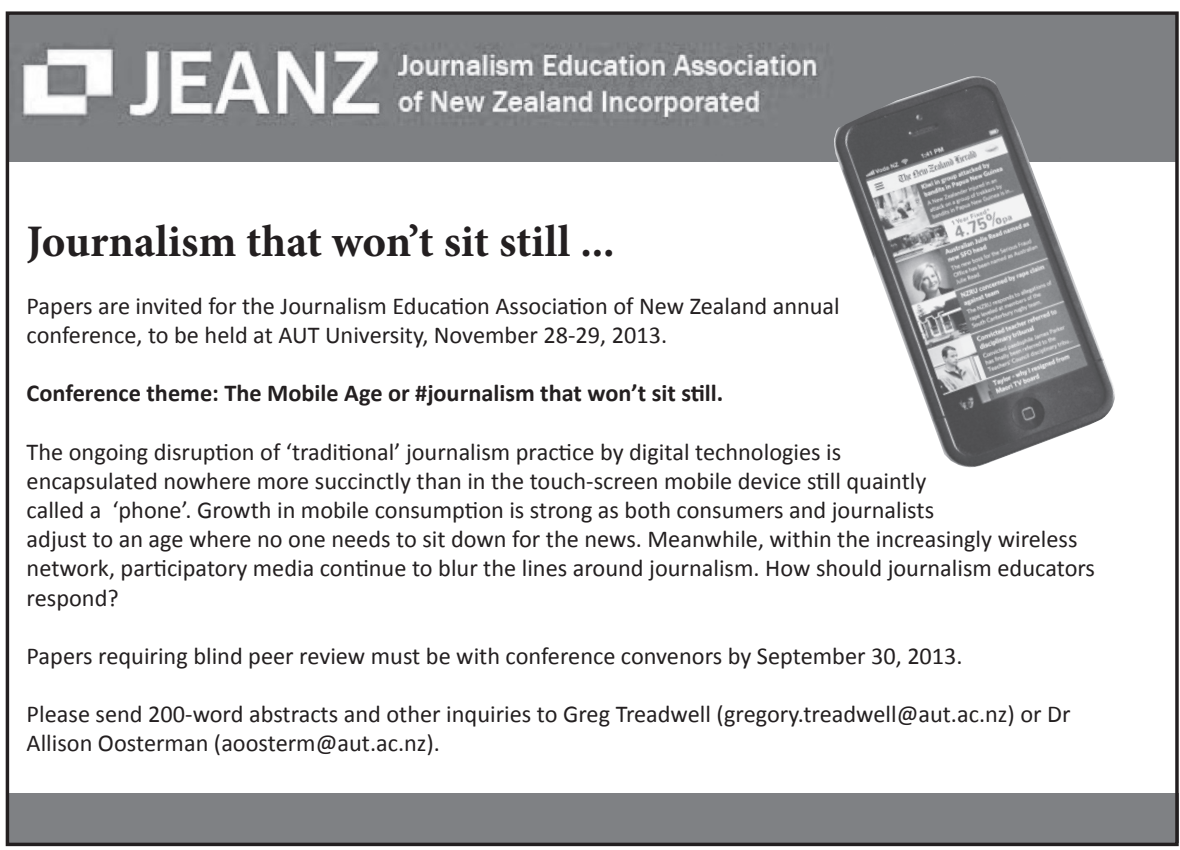

106 PACIFIC JOURNALISM REVIEW 19 (2) 2013 